\title{
Energy security management of a business entity
}

\author{
Vladimir Sulimin, Vladislav Shvedov, and Maiia Lvova \\ Ural State University of Economics, Yekaterinburg, Russia
}

\begin{abstract}
Nowadays, the basic indicator of the stability of an economic entity established to sell its products and obtain profits is its economic security, i.e. the protection of its interests regardless specific impact of different external and internal factors. The paper deals with the ways to ensure the entity energy system security, and measures to improve the efficiency of this system management. The paper also identifies the most typical threats to uninterruptible energy supply of enterprises and organizations, as well as means of preventing and overcoming problems caused by these problems.
\end{abstract}

\section{Introduction}

Technical security of the business entity energy system is considered an important component of its economic security. Uninterruptible energy supply necessary for the production process allows the organization to operate efficiently under current economic conditions [2].

To ensure its secure energy system operation a for-profit company must have a thoroughly planned order and systematic approach to implementing the set of methods and techniques that are applied to these systems and aimed at a certain result. The order involves the following aspects:

- $\quad$ providing the enterprise with energy from several sources, which are independent from one another;

- $\quad$ preventing negative environmental impacts of the energy system;

- $\quad$ systematic striving to minimize losses and waste;

- rational use of energy resources due to innovative technologies and equipment;

- $\quad$ training staff to use energy resources efficiently.

The operation planning, motivating, organizing, coordinating and controlling are carried out while implementing this order.

\section{Materials and methods}

Providing a balance in the interaction of separate elements of energy resources in order to establish the production proportions and growth rates, it is necessary to establish an equilibrium state between the available resources used for production and their estimated costs. In this case, it is essential to control and measure, substantiate and strictly comply 
with energy consumption standards, design the system of keeping records, minimize costs and losses.

All employees of the enterprise should be personally interested in the optimal energy consumption and saving. To ensure the conscientious and diligent staff attitude towards efficient energy consumption and saving it is important to create a special system of conditions and motives.

To manage the company's energy system efficiently and safely it is necessary to know its development strategy in terms of its reasonable energy consumption, resource possibilities, features of internal and external interaction of structures and elements [3].

Energy system safety and security control includes: a) monitoring the compliance of actual indicators with planned ones; $b$ ) maintaining the process of achieving the set goals.

Competent coordinated actions of officials to ensure the power supply system safety and security under conditions of internal and external impacts are aimed at increasing the efficiency of economic, environmental, and social components of the production process.

To provide a high level of protection of the business entity energy interests it is necessary to take into account a number of potential threats that can disrupt the stability of the energy consumption process:

- lack of financial assets attracted to the system technical development and improvement;

- irregular payment of costs on materials and components that are necessary for the smooth operation of equipment and mechanisms;

- unreasonably high costs of materials and equipment;

- unstable economic ties;

- monopolization of resources production, supply, and distribution;

- lack of balance between production and consumption of energy resources: insufficient capacity and low performance of switchgear and connecting lines;

- $\quad$ social instability causing negative socio-economic consequences;

- dishonest relationships between entrepreneurs, businessmen;

- $\quad$ illegal volitional actions of power bodies;

- criminal nature of many commercial activity areas in the fuel and energy complex;

- low level of specialized knowledge and skills demonstrated by managers and employees;

- accidents and failures due to poor quality of equipment as well as construction, repair, maintenance and operation work;

- $\quad$ significant wear of production mechanisms;

- $\quad$ ill-considered location of power system facilities;

- $\quad$ light-minded attitude to safety requirements;

- destruction and significant damage to systems caused by natural disasters (hurricanes, landslides, floods, etc.) or by natural anomalies (drought, solar radiation activity);

- $\quad$ poor coordination of ties between fuel and energy complex and other industries;

- insufficiently effective economic policy of the country, low level of implementation of the energy saving strategy due to imperfection of legislative and legal framework; imperfect instruments of regulation and control by the state[4].

In order to assess the impacts of the above-mentioned factors on the level of security of the business entity power supply system it is essential to consider the following things: the state and position of a given enterprise from the standpoint of the state of the industry in general; changes caused by the impact of various external and internal factors; the severity of possible energy threats; limit values leading to negative consequences after they are overcome. The guidelines to minimize the impact of different threats on the organization 
energy security have been developed while taking into account the study results and conclusions [6].

The following systems should be the objects of monitoring and control: fuel supply, power generation, transmission and distribution; environmental protection, relationships with consumers; management and financing. Fuel supply: recording of volumes, and types of used combustible substances and their reserves; payment. Power generation: determining capacity, types and the number of energy sources, and capacity reserves; establishing actual power generation. Power transmission: determining actual equipment wear and tear and its technical condition in general. Environmental protection: exclusion of environment pollution and harm to nature. Relationships with consumers: keeping agreements. Management and financing: high professional level of managers and employees, financial stability. While carrying out analysis it is important to follow the principles of the integrated approach, take into account internal and external relations of the system structural elements, and the priority of social stability as the main goal of the organization's economic security, its energy security being part of it.

Today Russia's economists and scientists pay great attention to studying problems of providing security of business entities power systems: L.S. Belyaev, V. V. Bushuev, N. I. Voropai, G. I. Kovalev (monitoring conditions, systematic researching energy supply and its protection); M. D. Ilyich, V. A. Stennikov, L. V. Vorobey, S. Ya. Chernavsky (influence of market laws on providing the organization's energy system security); B. I. Ayuev, E. A. Malysheva, V. S. Katrenko, N. L. Novikova ( enhancing energy supply management efficiency by using integrated processes in fuel-energy area); S. P. Filippov, L. M. Grigoriev, Yu. E. Nikolaev, B. I. Kudrin (forcasting activities to establish the system for protecting the company's energy supply); A. I. Kuzovkin, V. A. Volkonsky, V. Ya. Afanasyev, A. S. Dulesov (development of the system for providing energy to the organization, its management and protection).

Various methodological approaches to the issues of ensuring the energy security of business entities have been developed. They include: methods of studying systems, identifying scientific and practical problems; models of economic substantiation of energy security levels when they are under the influence of production structures as well as market rules of the system operation; economic and mathematical tools of forecasting the development of the organization's energy security system; mechanisms for managing the system operation and development [5].

\section{Elements of energy security}

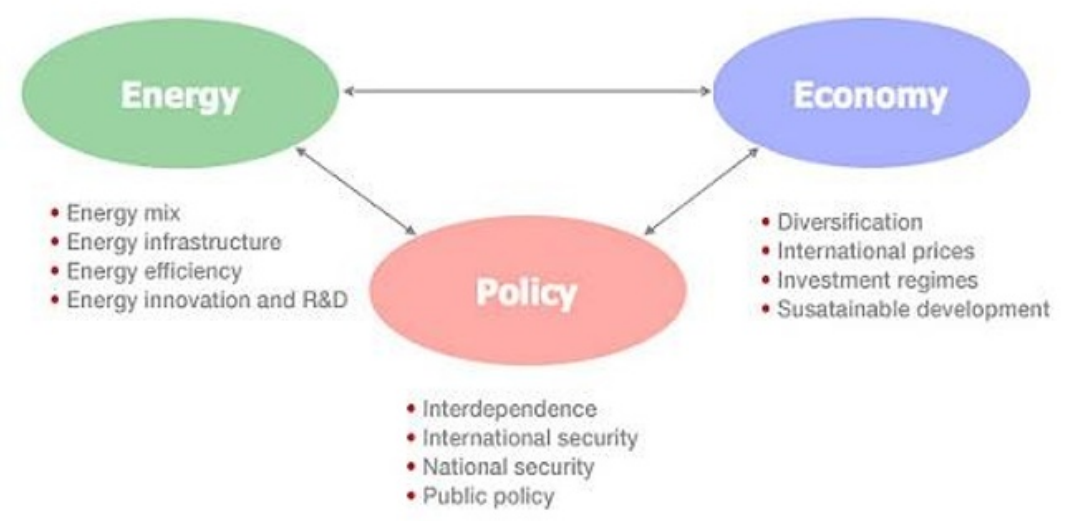

Fig. 1. Energy. Policy. Economy 
In practice, in order to improve the protection of energy supply systems of independent economic entities, which set goals of meeting the needs of society and make profits, the following measures are applied:

A. Organizational methods aimed at modernizing production processes: changing the beginning of the working day depending on the season; regulating lighting indoors according to the schedule; installing motion sensors, window opening and blinds adjusting sensors, having light controllers, which operate according to standard algorithms, changing the parameters of indoor heating depending on the season and the time of the day.

B. Taking into account the structural features of a building: use of the relief, exposure to sunlight, optimal location, wider window frames for better lighting and heating, use of special energy saving technologies and materials during the construction stage.

C. Minimizing lighting system energy consumption by controlling the lighting intensity, installing mechanisms to reduce mercury arch lamp energy consumption, replacing LED lighting devices with more modern and economical ones.

D. Improving systems that purify and cool air, e.g. while ventilating a room, providing the air passage through a tank containing cold water. This allows reducing the cost of cooling in summer and heating in winter. It is a good idea to use special devices that absorb the sun-light energy and convert it into heat, as well as equipment transferring heat energy from its sources to consumers. Installing heating devices that conduct heat by convection can also have a certain effect

E. Solar panels, tidal power plants, and wind turbines can be used as additional but currently not very reliable sources of energy.

F. Introducing special automatic electricity metering systems, which record equipment damage and technological processes failures to implement subsequent preventive and fixing measures.

G. Comprehensive management of all life support systems of the organization in order to maximize energy saving.

\section{Conclusion}

Thus, it is possible to efficiently manage the processes of ensuring energy security of the economically independent entity, which operates in order to meet the needs of society and obtain stable profits, provided that a number of important requirements are met. They involve [1]:

1. Active participation in the implementation of the national plan for the general energy system development.

2. Improvement of the energy security system management of business entities, the state playing the decisive role in that.

3. Systematic work to improve the quality and feasibility of energy sources usage.

4. Formation and development of the energy supply monitoring system.

\section{References}

1. T.E. Ivanova, M.A. Gavrilova, K.V. Skomoroshchenko, Economics, Entrepreneurship and Law, 8(3), 153 (2018)

2. A.O. Kokorin, Ecological Bulletin of Russia, 3, 34 (2016)

3. P.I. Razinkov, O. P. Razinkova, Bulletin of the Tver State Technical University. Series: Social Sciences and Humanities, 3, 121 (2017)

4. V.I. Salygin, R.K. Mustafinov, Economic Relations, 9(1), 177 (2019) 
5. S.V. Tishkov, V.V. Karginova-Gubinova, A.P. Shcherbak, A.D. Volkov, Issues of an innovative economy, 10(1), 387 (2020)

6. W. Gan, X. Ai, J. Fang, M. Yan, W. Yao, W. Zuo, J. Wen, Applied Energy, 239, 383 (2019)

7. T. Le, C.P. Nguyen, Energy Policy, 129, 436 (2019)

8. X. Liu, A. Liu, T. Wang, K. Ota, M. Dong, Y. Liu, Z.Cai, Journal of Parallel and Distributed Computing, 135, 140 (2020)

9. Z. Lv, W. Kong, X. Zhang, D. Jiang, H. Lv, X. Lu, IEEE Transactions on Industrial Informatics, 16(5), 3540 (2020)

10. C. Pahl-Wostl, Environmental Science and Policy, 92, 356 (2019)

11. D. Puthal, S.P. Mohanty, S.A. Bhavake, G. Morgan, R. Ranjan, IEEE Consumer Electronics Magazine, 8(3), 92 (2019)

12. P. K. S. Rathore, D. S. Chauhan, R. P. Singh, Renewable Energy, 131, 297 (2019)

13. A.K. Sangaiah, D.V. Medhane, G. Bian, A. Ghoneim, M. Alrashoud, M. S. Hossain, IEEE Transactions on Industrial Informatics, 16(5), 3322 (2020)

14. S.A.A. Shah, P. Zhou, G.D. Walasai, M. Mohsin, Ecological Indicators, 106 (2019)

15. G.B. Simpson, G.P.W. Jewitt, Frontiers in Environmental Science, 7(FEB) (2019)

16. F. Taghizadeh-Hesary, E. Rasoulinezhad, N. Yoshino, Energy Policy, 128, 796 (2019)

17. J. Zhou, J. Sun, P. Cong, Z. Liu, X. Zhou, T. Wei, S. Hu, IEEE Transactions on Services Computing, 13(4), 745 (2020) 